\title{
1 Church Bells and Ground Motions
}

2 Jordi Diaz

3 Institute of Earth Sciences Jaume Almera (ICTJA-CSIC), Barcelona, Spain

$4 \quad$ E-mail: jdiaz@ictja.csic.es

6 Abstract

7 Although the primary objective of seismic stations is the recording of waves generated by

8 natural seismicity, the sensors can detect vibrations generated by different sources of

9 natural and anthropogenic origin. The interest in identifying these sources has increased in

10 the last years with the use of background seismic vibrations to obtain images of the crustal

11 structure by tomographic methods and to monitor different natural processes. We present

12 here a very particular case of these type of sources, the bell ringing in churches to indicate

13 the passage of time. In some particular cases, the vibrations generated by the ringing of the

14 bells are recorded in seismic stations installed near the bell towers. We review different

15 examples throughout Europe of this particular kind of seismic records to illustrate how the

16 seismic records can provide information on the traditions followed to mark the hours in

17 some European countries, which turn out to be very different. The objective is not only to

18 publicize this curious records, but also to show that bridges can be built between very

19 different scientific disciplines, such as seismology and social sciences, since the seismic

20 data offers a new tool to researchers interested in investigating ethnographic aspects related

21 to how the passage of time is marked in different European cultures.

\section{Introduction}


24 Following the development of new techniques to use the vibrations recorded in the absence 25 of seismic waves, often referred to as "ambient seismic noise", to image the crustal

26 structure using tomographic methods (Campillo and Paul, 2003), interest in the sources of

27 the vibrations has increased significantly. In recent years, the study of these sources has led

28 to the development of the so-called environmental seismology, whose objective is to use

29 seismic data to monitor different natural processes, establishing connections between

30 seismology and other sciences, such as hydrology, meteorology or even biology. These

31 sources include natural phenomena, such as waves in the oceans (Stutzmann et al., 2009),

32 hurricanes (Sufri et al., 2014), wind (Johnson et al., 2019), river discharges (Díaz et al.,

33 2014), landslides and rock falls (Provost et al., 2018) or avalanches (Heck et al., 2019). In

34 addition, human activity is responsible for a large number of background vibrations,

35 particularly in urban environments. The main contributors to these anthropogenic signals,

36 often referred to as cultural noise, are road traffic (e.g. Riahi and Gerstoft 2015),

37 underground transport systems (Sheen et al., 2009), railways (Fuchs et al., 2017) or wind

38 turbines (Neuffer and Kremers, 2017). However, a wide variety of activities can generate

39 seismic signals in urban settings, including sporting events, musical concerts or fireworks

40 shows (Díaz et al., 2017).

42 In this contribution we will focus on a very particular case of a background vibration

43 source: the ringing of the bells in church bell towers that indicate the hours. Although the

44 potential use of such signals in Earth Sciences has not been explored yet, we believe that

45 our work is of interest to present this kind of curious recordings and to raise awareness in

46 other scientific disciplines on the possible use of seismic recordings in their research. 
48 In addition, our results document the different types of bell ringing used in several

49 European countries, showing that is possible to built bridges between very different

50 scientific disciplines, such as seismology and social sciences.

52 Broad-band seismometers can detect tiny ground movements in a large frequency band. As

53 the main objective of this equipment is to detect seismic waves generated by local or distant

54 earthquakes, the preferred locations for the stations are quiet areas, far from sources of

55 vibrations generated by natural or human sources. However, increasing requirements for

56 security, electrical power, access to the site, logistic installation requirements, etc., make it

57 often convenient, in particular for non-permanent deployments, to install seismic stations in

58 secure locations at or near small towns. Chapels and small churches are often a good

59 option, since most of the time they are not used and at the same time the instrumentation is

60 protected. However, an obvious negative counterpart from a seismological point of view is

61 that the instruments record bell rings.

62

\section{Seismic records of bell ringing}

64 Church bells have been used since the Middle Ages not only to mark masses and other

65 religious rituals, but also to mark the passage of time for the population. The canonical

66 hours, a division of the day into eight three-hour intervals, were marked by bells in

67 monasteries and some churches. In addition, the Angelus devotion started and spread out

68 over Europe in the twelfth century (Thurston, 1907). The Angelus devotion was

69 accompanied by the ringing of the Angelus bell, that had a double character as it marked

70 the moment of prayer but also the end of the working day 
71 Gradually, during the thirteenth century, a second Angelus call was introduced at noon to

72 mark lunch time. From the fifteenth century, a third call was introduced in the morning.

73 The manner of ringing the Angelus bell consists usually in a triple stroke of the bell,

74 repeated three times, a tradition that remained strong until the early twentieth century and

75 still is preserved in some regions. Since the beginning of the fifteenth century, mechanical

76 striking clocks began to be installed in the most important churches. The bell towers began

77 then to act as public clocks, using the bells to announce the time marked by mechanical

78 clocks. By the end of the 16th century, many churches in Europe had already installed

79 mechanical clocks. However, it was in the mid-nineteenth century, after a significant

80 reduction of the production costs of clocks, when the use of church bells to indicate civil

81 times began to be common in many cities. In this contribution, we present examples of the

82 different traditions followed in Europe to indicate the pass of time using the bell ringing. To

83 do this, we use seismic data retrieved from broad-band seismic stations installed near tower

84 bells at four sites located in Greece (Western Peloponnese), Italy (Calabria), southern

85 France (Dordogne) and NE Iberia (Catalonia). The details of each location are summarized

86 at Table 1. Although signals are clear, a high-pass filter with a corner frequency of $5 \mathrm{~Hz}$ has

87 been applied to suppress eventual long period signals. As discussed below, the recorded

88 signals in each of the investigated places differ greatly, reflecting differences in cultural and

89 religious traditions (Fig.1).

90 a) Riolos, Western Peloponnesus, Greece

91 The RLS seismic station is located in the Riolos Kato Achaia town (W Peloponnese,

92 Greece) and integrated into the Greek national seismic network (National Observatory of

93 Athens, Institute of Geodynamics, 1997). The seismic station is installed in a small building

94 near the church. As with all the examples presented later, the seismometer records the 
95 vibrations generated by the chimes as short and impulsive signals with an amplitude clearly

96 higher than the background seismic noise. In this case, the hourly announcements begin at

97 7:00 local time and stop at 13:00. The bell rings again at 17:00 and remain active until

98 21:00 (Fig. 2). This schedule shows that this community has chosen to preserve the rest

99 time not only during the night hours, but also after lunch, suppressing the chimes during

100 these intervals. Rest periods during the central hours of the day are common in countries

101 around the Mediterranean Sea and are related to the high temperatures that are often felt

102 during the summer. The schedule of bells in Riolos seems to accommodate this tradition.

104 Each hour is indicated by the corresponding number of strikes and the interval between

105 each stroke is close to 2 seconds. Half hours are announced with a double strike of smaller

106 amplitude. By the way, in this particular case, seismic data allow us to note that the clock is

107 delayed about 2 minutes and 20 seconds, a delay that increases slightly with time (see

108 dashed lines in Fig. 2).

109

110 b) Lunas, Dordogne, SW France

111 During the temporary deployment of the Pyrope seismic network (Chevrot, S., Sylvander,

112 M., 2017), a broad-band station was installed near the church of Lunas, a small town in the

113 Dordogne region of southwestern France, and remained active between September 2011

114 and May 2013. Recordings of this station show that the bell rings between 7:00 to 20:00

115 local time, without interruption in the early afternoon. The interval between each bell strike

116 is close to $2.2 \mathrm{~s}$ and the full stroke is repeated 2 minutes after the sound of the last bell of

117 the first call (Fig. 3). This is a common tradition in different areas and has a practical

118 utility, since it was not easy for people working outside to realize the amount of strikes on 
119 the first call. As in the Greek example, the half hours are also signaled, in this case by a 120 single strike of the bell.

122 It is interesting to note that the medieval tradition of the Angelus is preserved at this place.

123 Three times a day, after the bell ringings at 07:00, 12:00 and 19:00, the Angelus is marked

124 by a triple stroke of the bells repeated three times, separated by 8 seconds (red ellipses in

125 Fig. 3). This manner of ringing has seems to have remained unchanged since the Middle 126 Ages.

129 The following example presents the records acquired at temporary station E120, deployed

130 in the small village of Sta Maria Montmagastrell, located in Catalonia, NE Spain. This

131 station was installed as part of the Topolberia-Iberarray deployment (ICTJA-CSIC, 2007)

132 and has been operational between March and September 2011, after which was moved to a

133 more quiet location. Bell ringing is active here from 07:00 till 22:00 local time. This

134 schedule reflects the fact that nighttime hours begin later in Spain, where the usual dinner

135 time is between 20:30 and 22:00, than in the Greek of French locations analyzed

136 previously. However, we are aware that it is dangerous to make general conclusions from a

137 single observation and in fact we know from personal observations that in some towns in

138 the same region, the bells sound during the whole night.

140 The chimes are separated by 2.4 seconds, and, as in the previous example, the bell strokes

141 are repeated a couple of minutes later. It is curious to note that in the southwestern France

142 site, the second stroke starts 2 minutes after the end of the main one, while in the NE Spain 
143 case, the second stroke is played 2 minutes after the beginning of the first. This small

144 difference results in a notorious change in the pattern of the daily plots, as noted comparing

145 Fig. 4a and Fig. 3.

147 A particular characteristic of the manner of ringing is this location is given by how the hour

148 quarters are indicated. As seen in Fig. 4b, smaller ringing bells are played every quarter and

149 the exact hours bell calls are preceded by the four strikes, one for each quarter. This fact is

150 directly related to the traditional way to marking the hours, half-hours and quarter-hours in

151 Catalonia, where, as example, 08:15 is referred as "one quarter of nine", 08:30 as "two

152 quarters of nine and 8:45 as "three quarters of nine".

153

154 d) Oriolo, Calabria, S. Italia

155 The ORI station is located in the town of Oriolo, in the region of Calabria in southern Italy,

156 and belongs to the Italian Seismic network (Istituto Nazionale di Geofisica e Vulcanologia,

157 2006). Seismic records related to bell ringing show a complex pattern, with clear

158 differences from the previous examples (Fig. 5).

159

160 Firstly, the hourly rings cover the entire day, including night hours. Secondly, each hour

161 quarter is marked following a particular tradition. As observed in Fig. 5, every 15 minutes,

162 the bell stroke includes the number of chimes corresponding to the previous hour and the

163 number of smaller amplitude strikes corresponding to the quarter (Fig. 5). As an example,

$1649: 30$ will the marked by 9 large chimes and 2 additional, smaller strikes. The strikes of the

165 bells are separated 1.7 seconds and the bell stroke marking the quarters start three seconds

166 after the last chime of the loudest bells. As can be easily calculated, this tradition results in 
167 a total of 768 bell strikes during a single day, a that does not seem to disturb local 168 population.

\section{Discussion and Conclusions}

171 We have shown how seismic recordings can be used to document the different traditions

172 followed in Europe to mark the hours using striking clocks installed in bell towers. Of

173 course, other instrumentation, such as microphones, would be more appropriate to do this

174 type of research, but this contribution proves that existing seismic data, all publicly

175 available, can be used for purposes very different from those usually considered in Earth

176 sciences.

177

178 Two mechanisms can be invoked to explain the seismic recordings of bell ringing. First, the 179 recordings may correspond to the vibration of the bell tower during the strikes, which is

180 transmitted to the ground producing a movement that is recorded by the seismic sensor.

181 Secondly, the recordings can be generated by the sonic waves produced by the bells and

182 converted to mechanical vibrations close to the seismometer. Examples of acoustic signals

183 recorded on seismometers are common, including sonic booms generated by airplane shock

184 waves (https://blogs.ei.columbia.edu/2016/02/04/the-earth-shook-but-it-wasnt-an-

185 earthquake/), explosions of bolides entering in the atmosphere (Hedlin et al., 2010),

186 firework shows (Díaz et al., 2017) or accidental explosions in industrial plants (Schneider

187 et al., 2018). Although discriminating between the two phenomena is not evident without

188 collocated microphones, the inspection of the frequency content of the signals can provide

189 some ideas about the origin of such signals. Fig. 6 shows the spectrogram of the signals 
190 recorded during bell ringings in the four sites. In all cases, the energy extends over the

191 entire frequency range, from 0.1 to $50 \mathrm{~Hz}$, the maximum frequency that can be explored

192 with our dataset. Hinzen et al (2012), analyzed the frequency content of the seismic signals

193 recorded during the ringing of a large bell in the Cologne Cathedral, observing the largest

194 response amplitudes at $0.833 \mathrm{~Hz}$, a value falling between the first and second

195 eigenfrequencies of the tower. In our cases, the largest amplitudes are observed at

196 frequencies ranging between $10 \mathrm{~Hz}$ (Lunas) and $37 \mathrm{~Hz}$ (Sta Maria M.). These values are far

197 from the natural frequencies of bell towers, hence favoring the hypothesis of an

198 acoustic/mechanical coupling near the seismometers, although a modeling effort, out of the

199 scope of this paper, will be needed to confirm or not this point.

201 The RLS station in Greece shows maximum amplitudes at frequencies between 10 and 40

$202 \mathrm{~Hz}$, with a clear decrease for higher and lower frequencies. The site in SW France shows

203 maximum amplitudes between 1 and $20 \mathrm{~Hz}$, with a secondary maximum between 25 and 45

204 Hz. E120 in NE Spain also shows two energy packets but in this case the most energetic

205 ranges between 25 and $50 \mathrm{~Hz}$, while the secondary package has lower frequencies, in the 1-

$20625 \mathrm{~Hz}$ band. The frequency content of the bell strikes signaling the quarters and the hours

207 are similar, with only minor differences in the energy content of the high frequency band.

208 In the ORI station in southern Italy the energy is uniformly distributed along the

209 spectrogram, although the 5 to $30 \mathrm{~Hz}$ band has a slightly higher level of energy. These

210 minor differences in the frequency content of the signals are probably related to variations

211 in the distance between the bells and the seismometer, to structural differences in bell

212 towers or to changes in the subsoil properties between the sites investigated. A detailed 
213 modeling of each case, which is out of the scope of this paper, would be necessary to fully

214 understand the origins of the signals.

216 It must be pointed that, although disturbed by bell ringing, these stations successfully

217 perform their main task, that is, record the arrival of seismic waves generated by

218 earthquakes. Sometimes, seismic waves are detected close to bell ringing times, giving the

219 opportunity to compare the relative amplitudes of both features. Fig. 7 shows two examples

220 of such cases, one displaying the arrival of seismic waves from a regional event and the

221 second one showing seismic waves from a distant earthquake. In the first case, the data

222 acquired in RLS show the arrival of the body waves generated by a regional earthquake of

223 local magnitude 3.5 and epicenter near the town of Chakida, at a distance of about $180 \mathrm{~km}$

224 of Riolos, some seconds before an hourly bell strike. In the second example, the P-waves of

225 a large earthquake of magnitude 7.1 near the east coast of Honshu, Japan, arrive at the Sta

226 Maria de Montmagastrell station (NE Spain) after a $10.000 \mathrm{~km}$ trip few seconds before the

$227 \quad 16: 45$ bell strike.

229 From a seismological point of view, the seismic recordings of bell ringing can be used to

230 perform studies analyzing the relative contribution of sonic and mechanical waves to the

231 detected ground motion or to evaluate amplification factors for each specific site. Having a

232 large number of repetitive sources can also allow to investigate possible time variations in

233 amplification or frequency contents, using auto-correlation techniques (Sánchez - Pastor et

234 al., 2019), a point that could be related to changes in the mechanical properties of the

235 subsoil due, for example, to variations in the groundwater level. Regarding the interest of 
236 this contribution for the social sciences, we are aware that significant changes in bell

237 ringing can occur between close locations, sometimes because of very specific problems.

238 As an example, today in Spain there is an open discussion about whether the chimes should

239 be suppressed or not during the night hours. Each municipality tends to make its own

240 decision, so it is difficult to extend our observations at regional or national level. Even so,

241 we believe that our work, beyond presenting a curious kind of seismic record, can

242 contribute to a better understanding of the different traditions still active in Europe to mark

243 the hours and may encourage more exhaustive studies on this topic using acoustic or

244 infrasound detectors. Additionally, we believe that this survey can be used to reach an

245 audience that does not usually worry about seismic records, to bring new collaborations

246 with social sciences such as ethnography, and to contribute to the development of the so-

247 called "citizen seismology", seeking to involve citizenship with the seismic observations

248 (e.g. Subedi et al. 2020, Diaz et al., 2020).

\section{Data and Methods}

251 Seismic data used in this contribution were collected as part of the TopoIberia-Iberarray

252 and Pyrope temporary deployments and from permanent stations from the Italian and Greek

253 seismic networks. The Orfeus EIDA node ( https://www.orfeus-eu.org/data/eida ,

$254 \mathrm{http} / /$ doi.org/10.17616/R3V06T ) was used to get access to the seismic data.

255 Many of the Figs of this contribution were produced using the Generic Mapping Tools

256 (GMT) software (Wessel, P., Smith, W.H.F., Scharroo, R., Luis, J., Wobb, 2013) 
259 This work has been partially supported by the Generalitat de Catalunya grant 2017SGR1022

260 and the SANIMS project (RTI2018-095594-B-I00), funded by the Spanish Ministery of 261 Science, Innovation and Universities. 
264 Fig. 1: Examples of seismic recordings with bell ringing signals in four European

265 locations. Each plot corresponds to one day, and each trace represents the same minute at 266 every hour on that day. Time scale is in seconds relative to the origin of the line.

268 Fig. 2: Bell ringing in Riolos (Greece) on July 6, 2019. Each line shows one minute and a 269 line is shown every 30 minutes, from 00:00 to 23:59 UTC on July 6, 2019 (3:00 02:59

270 Greek local time). The dashed line shows the increasing delay in the bell clock.

Fig. 3: Bell ringing in Lunas, SW France. a) Daily data for June 29, 2012 (02:00 01:59

273 French local time). Each line shows 3.5 minutes and there is one line per hour. Observe the

274 second strike 2 minutes after the first and the Angelus strikes, shown by red ellipses.

275

276 Fig. 4: Bell ringing in Sta Maria Montmagastrell (NE Spain) a) Daily recordings during 277 April 1, 2011 (02:00 01:59 local time). Each line shows 200 seconds and there is one line 278 per hour. b) Chimes between 12:00 and 13:00 local time, showing the bell ringing used to 279 mark quarters. Each line shows one minute of signal and there is one line every 15 minutes.

281 Fig. 5: Belt ringing in Oriolo, S Italy during July 21, 2019 (02:00 01:59 Italian local 282 time). Each line shows one minute and there is one line every 15 minutes.

284 Fig. 6: Spectrograms of the four sites investigated. a) Riolos, Greece (6/7/2019) b) Lunas, 285 SW France $(29 / 6 / 2012)$ c) NE Spain (1/4/2011) and d) Oriolo in southern Italy 
286 (21/7/2019). In all cases a one-minute long signal is shown, varying the color palette to 287 better represent the recorded amplitudes.

289 Fig. 7: Examples of regional and teleseismic events arriving at times close to the bell 290 strikes. a) Regional earthquake (magnitude 3.5, 19/7/2019) recorded some seconds before 291 20:00 bell ringing at station RLS (Riolos, Greece). b) Teleseismic P-waves form a 292 magnitude 7.1 earthquake in Japan (7/4/2011) reaching the E120 station in northeastern 293 Spain a few seconds after the 16:45 bell strike. 


\section{References}

296 Campillo, M., Paul, A., 2003. Long range correlations in the diffuse seismic coda. Science

297 (80-. ). 299, 547-549. https://doi.org/10.1126/science.1078551

298 Chevrot, S., Sylvander, M., \& R., 2017. Seismic network X7:PYROPE PYRenean

299 Observational Portable Experiment (RESIF-SISMOB). RESIF - Réseau Sismologique

300 et géodésique Français. [WWW Document].

301 https://doi.org/https://doi.org/10.15778/RESIF.X72010

302 Díaz, J., Ruíz, M., Crescentini, L., Amoruso, A., Gallart, J., 2014. Seismic monitoring of an

303 Alpine mountain river. J. Geophys. Res. Solid Earth 119.

$304 \quad$ https://doi.org/10.1002/2014JB010955

305 Díaz, J., Ruiz, M., Sánchez-Pastor, P.S., Romero, P., 2017. Urban Seismology: On the

306 origin of earth vibrations within a city. Sci. Rep. 7. https://doi.org/10.1038/s41598-

$307 \quad 017-15499-\mathrm{y}$

308 Diaz J, Schimmel M, Ruiz M, Carbonell R (2020) Seismometers Within Cities: A Tool to

309 Connect Earth Sciences and Society. Front Earth Sci 8:1-7.

310 https://doi.org/10.3389/feart.2020.00009

311 Fuchs, F., Bokelmann, G., Group, W., 2017. Equidistant Spectral Lines in Train Vibrations

$312 \quad$ XX, 1-11. https://doi.org/10.1785/0220170092

313 Heck, M., Van Herwijnen, A., Hammer, C., Hobiger, M., Schweizer, J., Fäh, D., 2019.

314 Automatic detection of avalanches combining array classification and localization.

315 Earth Surf. Dyn. 7, 491-503. https://doi.org/10.5194/esurf-7-491-2019

316 Hedlin, M.A.H., Drob, D., Walker, K., Hedlin, C.D.G., 2010. A study of acoustic 
propagation from a large bolide in the atmosphere with a dense seismic network 115 ,

318 1-17. https://doi.org/10.1029/2010JB007669

319 Hinzen KG, Fleischer C, Schock-Werner B, Schweppe G (2012) Seismic surveillance of

320 cologne cathedral. Seismol Res Lett 83:9-22. https://doi.org/10.1785/gssrl.83.1.9

321 ICTJA-CSIC, 2007. TopoIberia-IberArray seismic network. International Federation of

322 Digital Seismograph Networks [WWW Document].

323 https://doi.org/doi.org/10.7914/SN/IB

324 Istituto Nazionale di Geofisica e Vulcanologia, I., 2006. INGV Seismological Data Centre.

325 Rete Sismica Nazionale (RSN). [WWW Document].

326 https://doi.org/doi.org/10.13127/SD/X0FXNH7QFY

327 Johnson, C.W., Meng, H., Vernon, F., Ben - Zion, Y., 2019. Characteristics of Ground

328 Motion Generated by Wind Interaction With Trees, Structures, and Other Surface

329 Obstacles. J. Geophys. Res. Solid Earth 8519-8539.

330 https://doi.org/10.1029/2018jb017151

331 National Observatory of Athens, Institute of Geodynamics, A., 1997. National Observatory 332 of Athens Seismic Network. https://doi.org/10.7914/SN/HL

333 Neuffer T, Kremers S (2017) How Wind Turbines Affect the Performance of Seismic

334 Monitoring Stations and Networks. 1-14. https://doi.org/10.1093/gji/ggx370

335 Provost, F., Malet, J.P., Hibert, C., Helmstetter, A., Radiguet, M., Amitrano, D., Langet, N.,

336 Larose, E., Abancó, C., Hürlimann, M., Lebourg, T., Levy, C., Le Roy, G., Ulrich, P.,

337 Vidal, M., Vial, B., 2018. Towards a standard typology of endogenous landslide

338 seismic sources. Earth Surf. Dyn. 6, 1059-1088. https://doi.org/10.5194/esurf-6-1059-

2018 
340 Riahi, N., Gerstoft, P., 2015. The seismic traffic footprint: Tracking trains , aircraft, and

341 cars seismically 2674-2681. https://doi.org/10.1002/2015GL063558.Received

342 Sánchez - Pastor, P., Obermann, A., Schimmel, M., Weemstra, C., Verdel, A., Jousset, P.,

343 2019. Short - and long - term variations in the Reykjanes geothermal reservoir from

$344 \quad$ seismic noise interferometry. Geophys. Res. Lett. 2019GL082352.

345 https://doi.org/10.1029/2019GL082352

346 Schneider, F.M., Fuchs, F., Kolínský, P., Caffagni, E., Serafin, S., Dorninger, M.,

347 Bokelmann, G., 2018. Seismo-acoustic signals of the Baumgarten (Austria) gas

348 explosion detected by the AlpArray seismic network. Earth Planet. Sci. Lett. 502,

$349 \quad$ 104-114. https://doi.org/10.1016/j.eps1.2018.08.034

350 Sheen, D.H., Shin, J.S., Kang, T.S., Baag, C.E., 2009. Low frequency cultural noise.

351 Geophys. Res. Lett. 36, 1-5. https://doi.org/10.1029/2009GL039625

352 Stutzmann, E., Schimmel, M., Patau, G., Maggi, A., 2009. Global climate imprint on

$353 \quad$ seismic noise. Geochemistry, Geophys. Geosystems 10.

354 https://doi.org/10.1029/2009GC002619

355 Subedi S, Hetényi G, Denton P, Sauron A (2020) Seismology at School in Nepal: A

356 Program for Educational and Citizen Seismology Through a Low-Cost Seismic

357 Network. Front Earth Sci 8:. https://doi.org/10.3389/feart.2020.00073

358 Sufri, O., Koper, K.D., Burlacu, R., Foy, B. De, 2014. Microseisms from Superstorm

359 Sandy. Earth Planet. Sci. Lett. 402, 324-336.

$360 \quad$ https://doi.org/10.1016/j.eps1.2013.10.015

361 Thurston, H., 1907. Angelus [WWW Document]. Cathol. Encicl. Vol 1, New York, Robert 362 Applet. Co. 
363 Wessel, P., Smith, W.H.F., Scharroo, R., Luis, J., Wobb, F., 2013. Generic Mapping Tools . 364 Eos (Washington. DC). 94.

365 


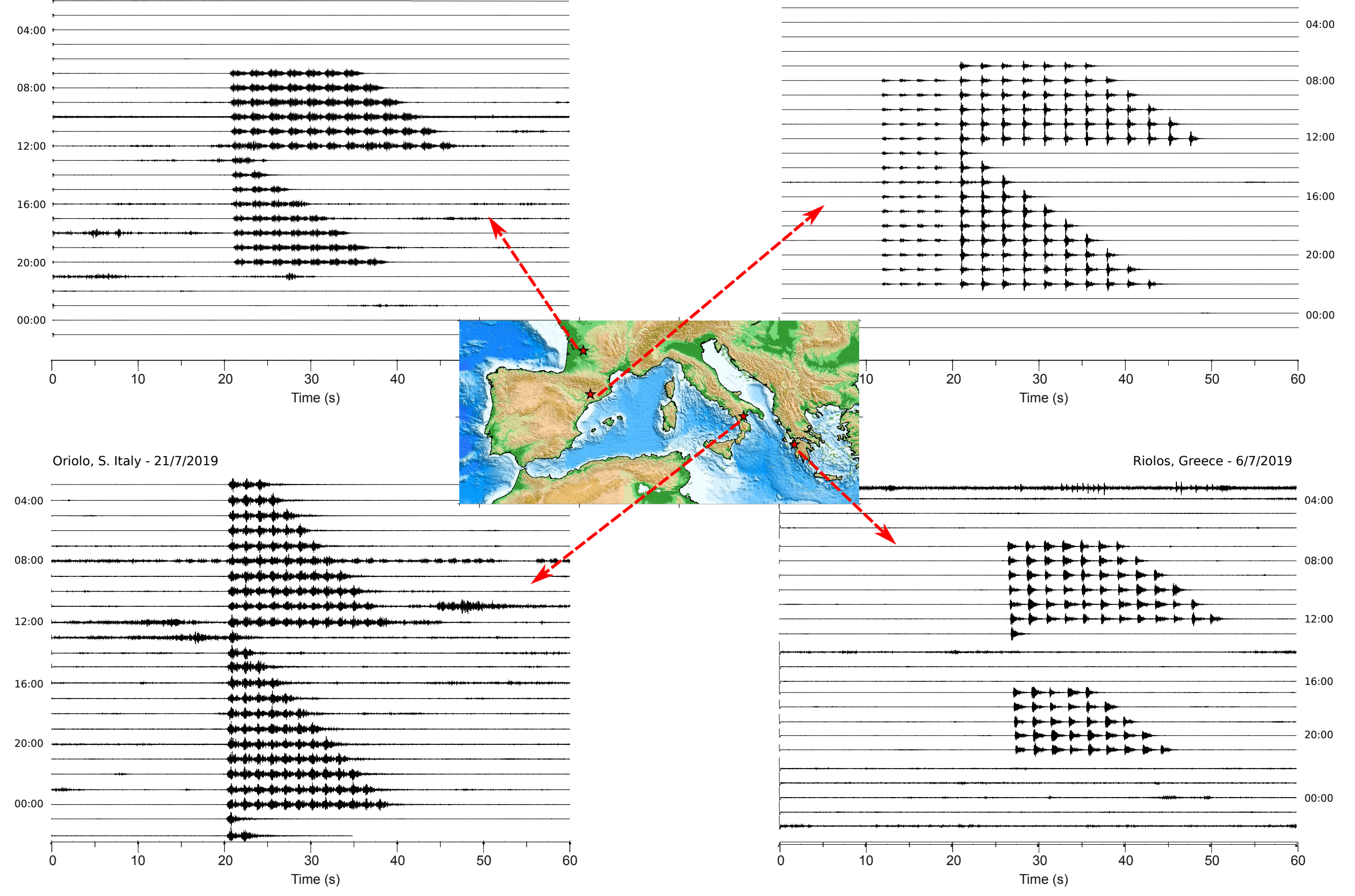




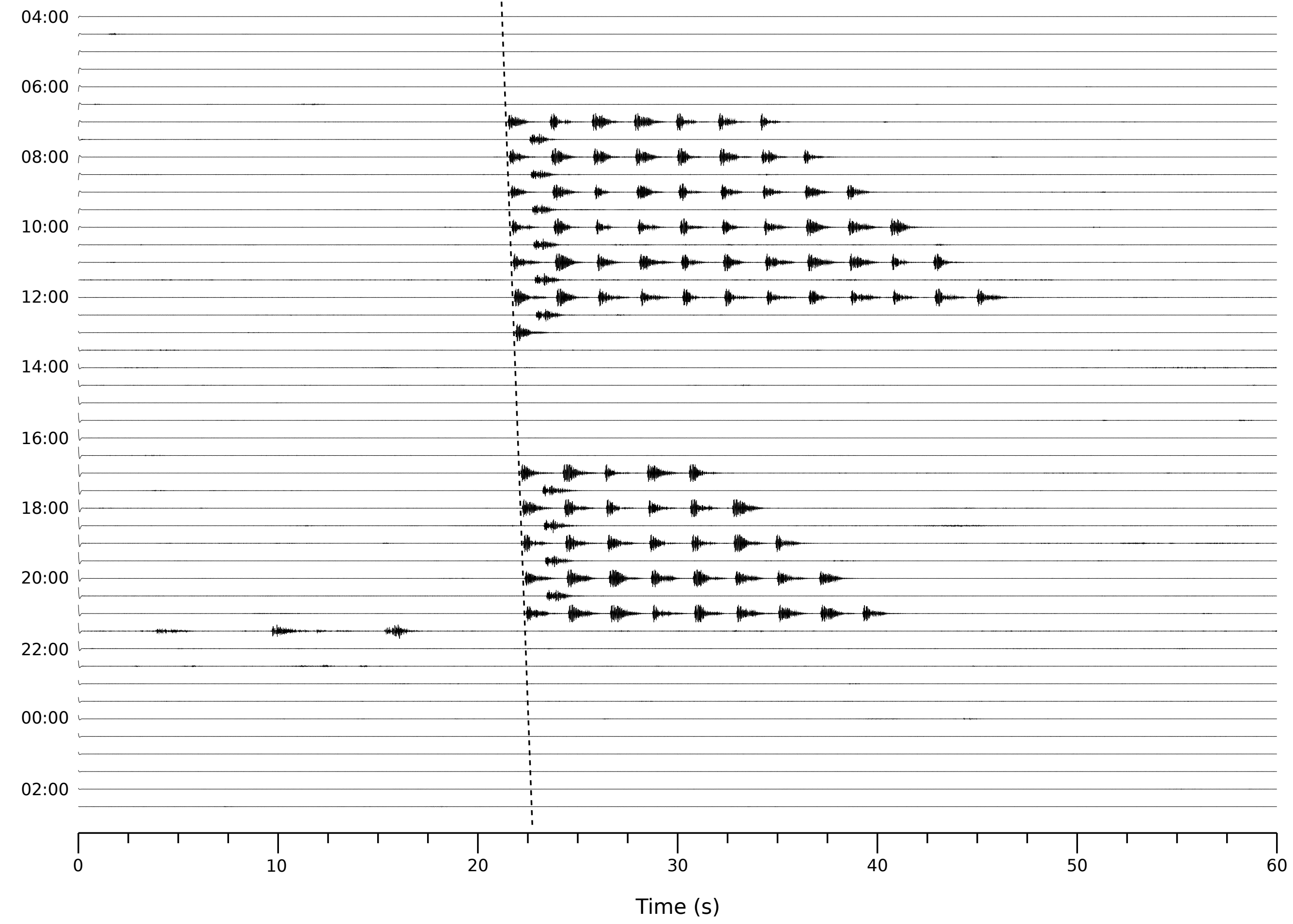

Figure

Figure

Figure

Figure

Figure

Figure

Figure

Figure

Figure 


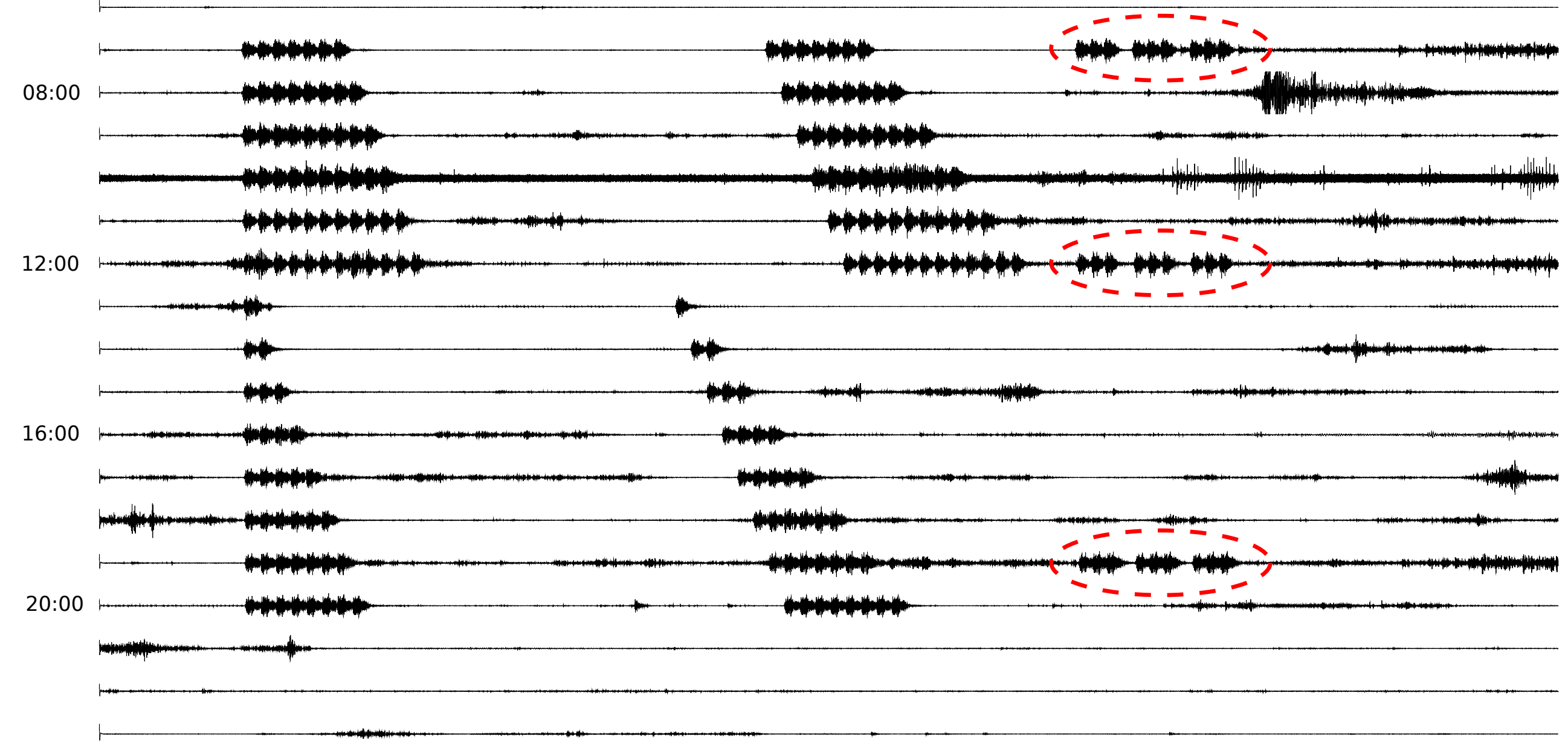

00:00

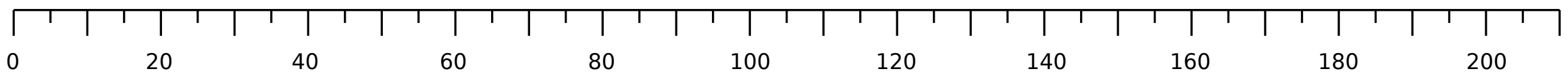

Time (s) 
a)

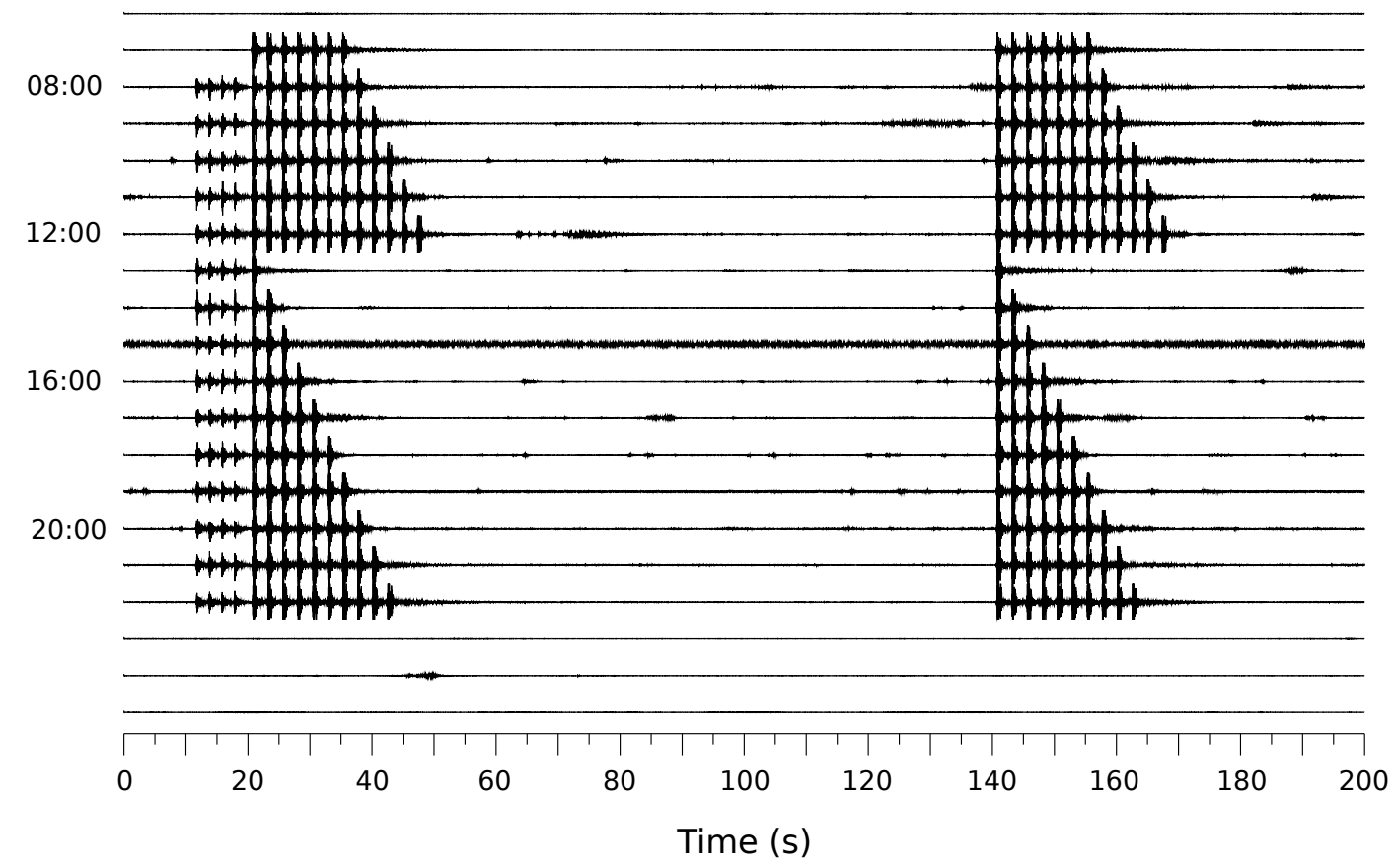

b)
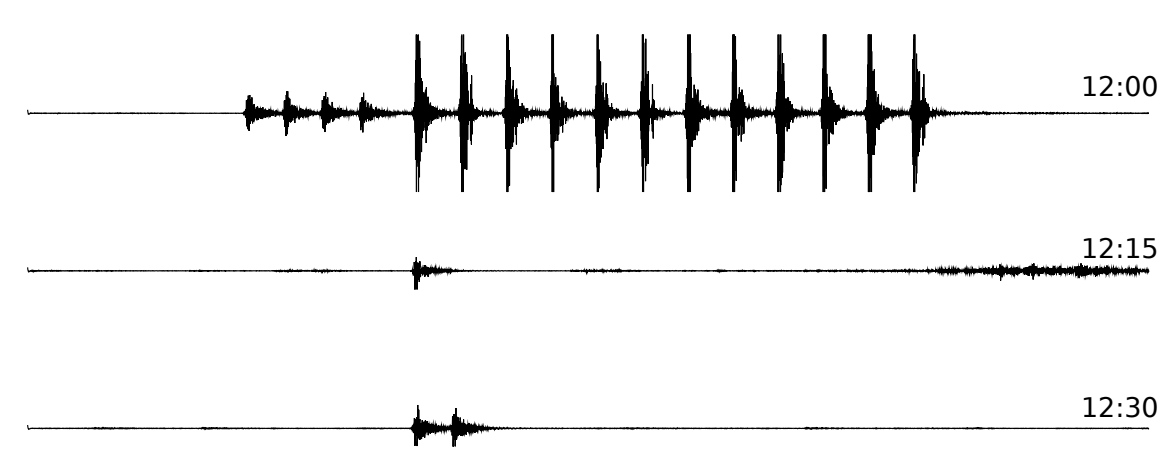

$12: 45$

13:00

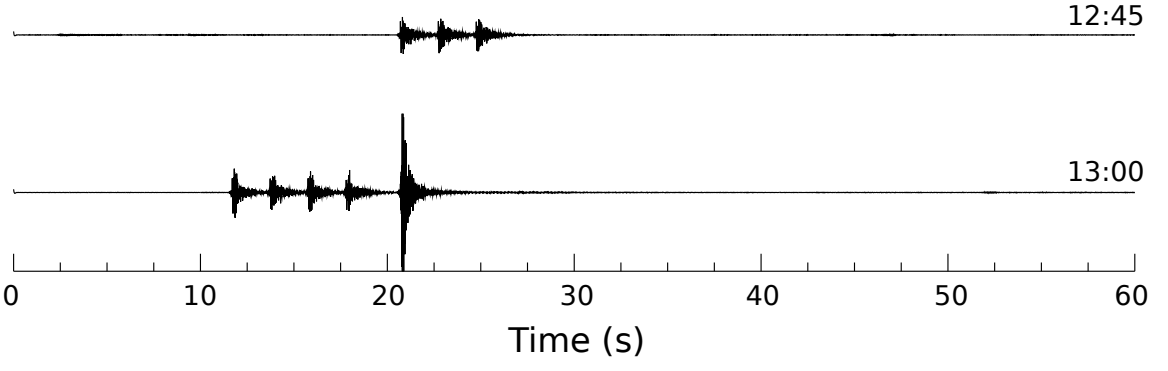




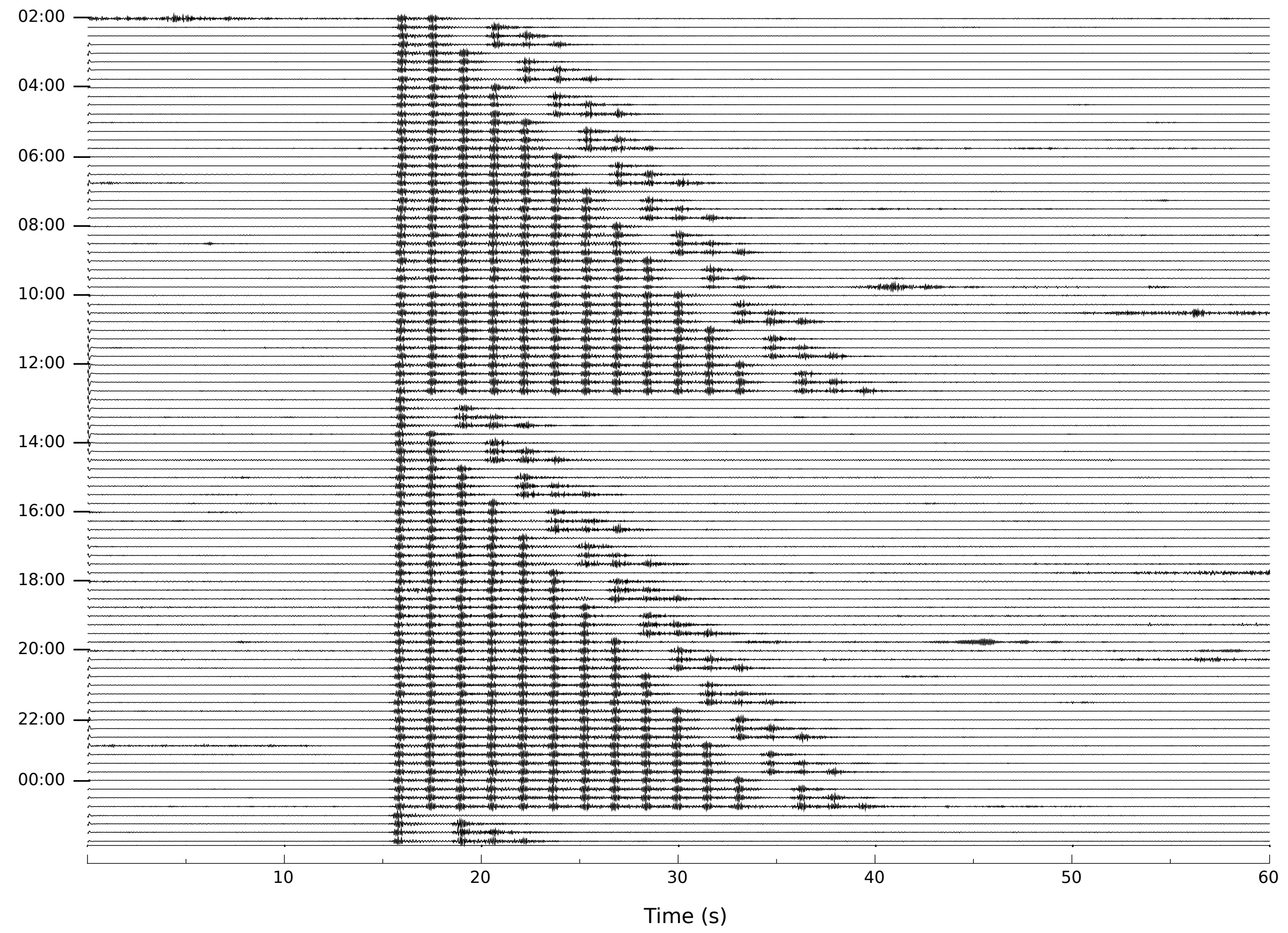


Riolos, Greece

a)

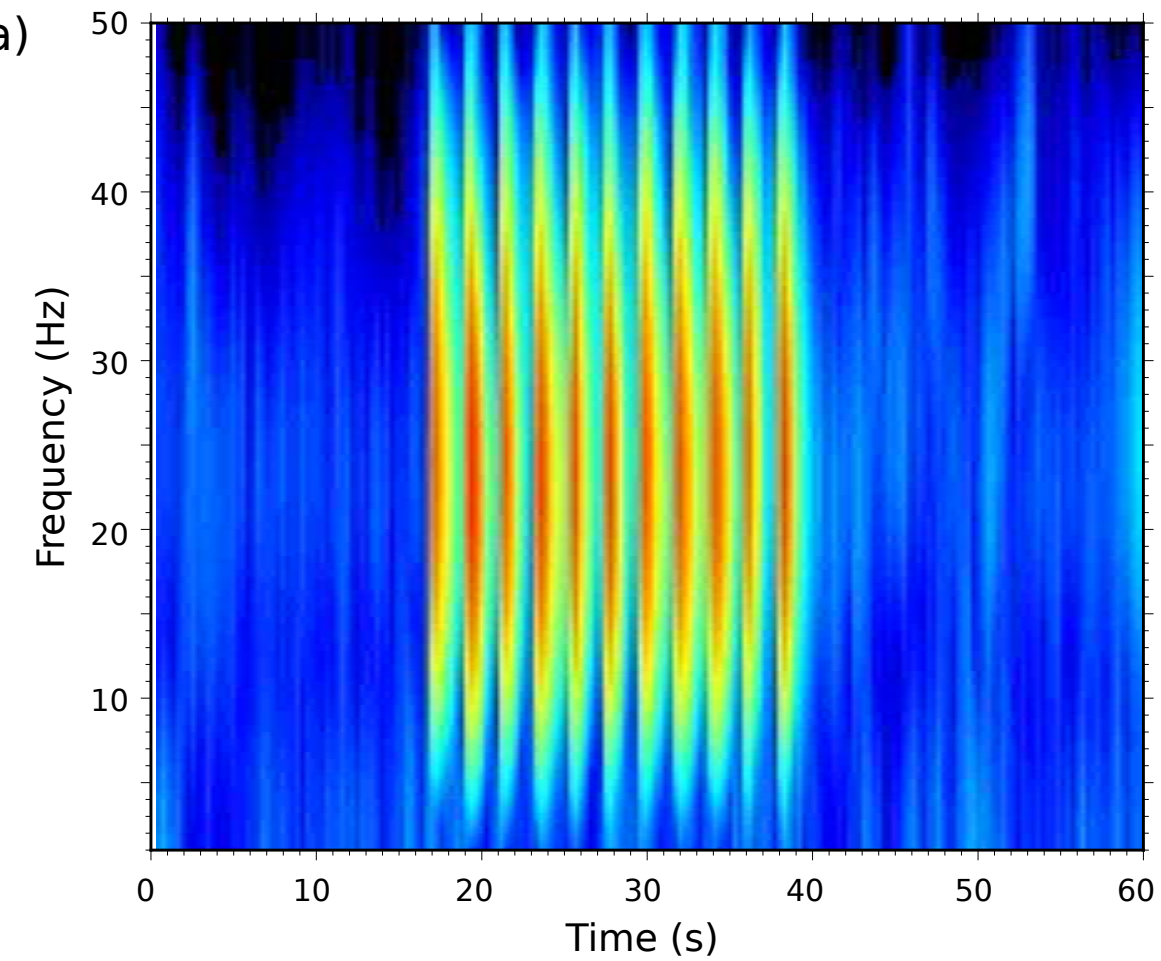

Sta. Maria Montmagastrell, SE Spain

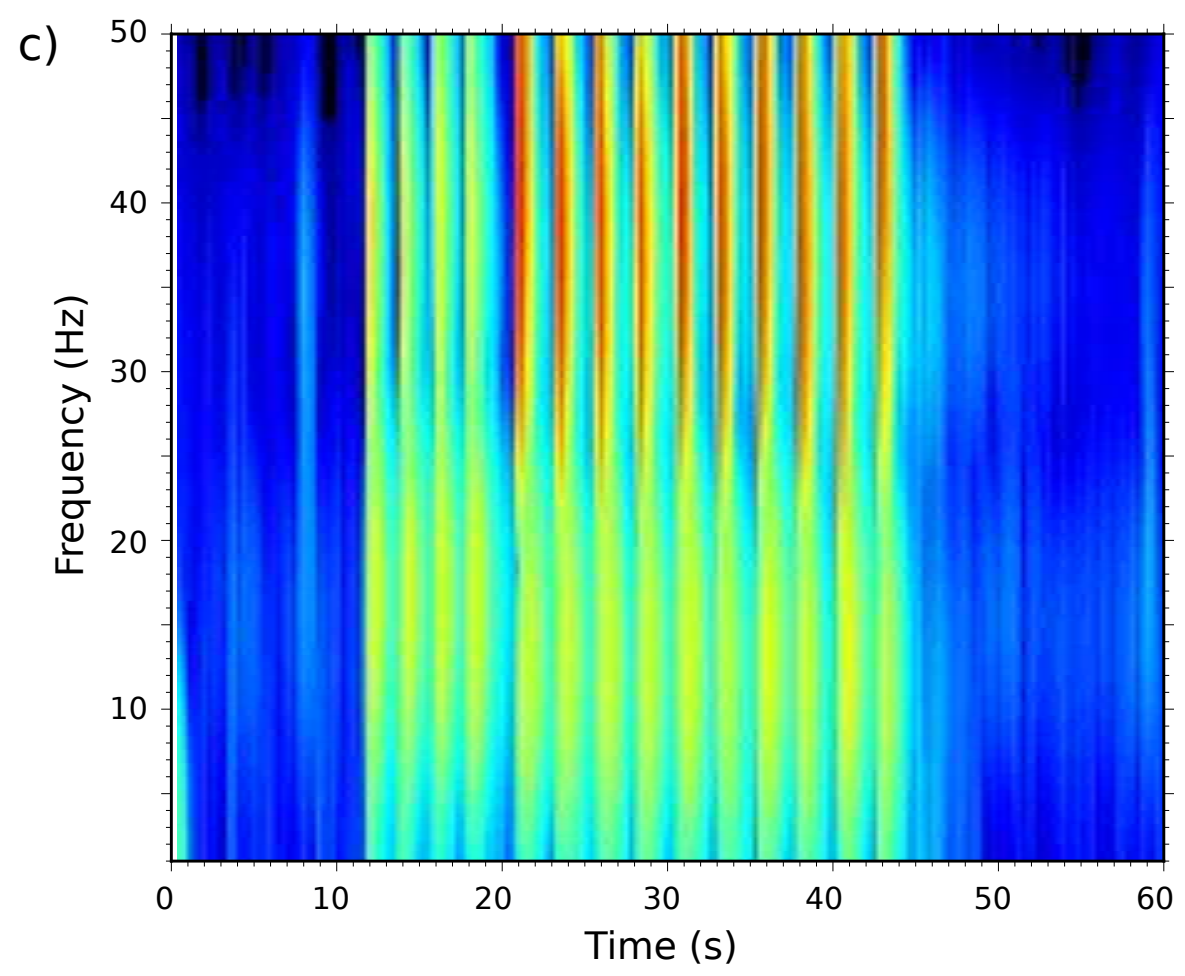

Lunas SW France Click here to access/download;colour figure;Fig6.eps $\underline{\underline{\underline{*}}}$
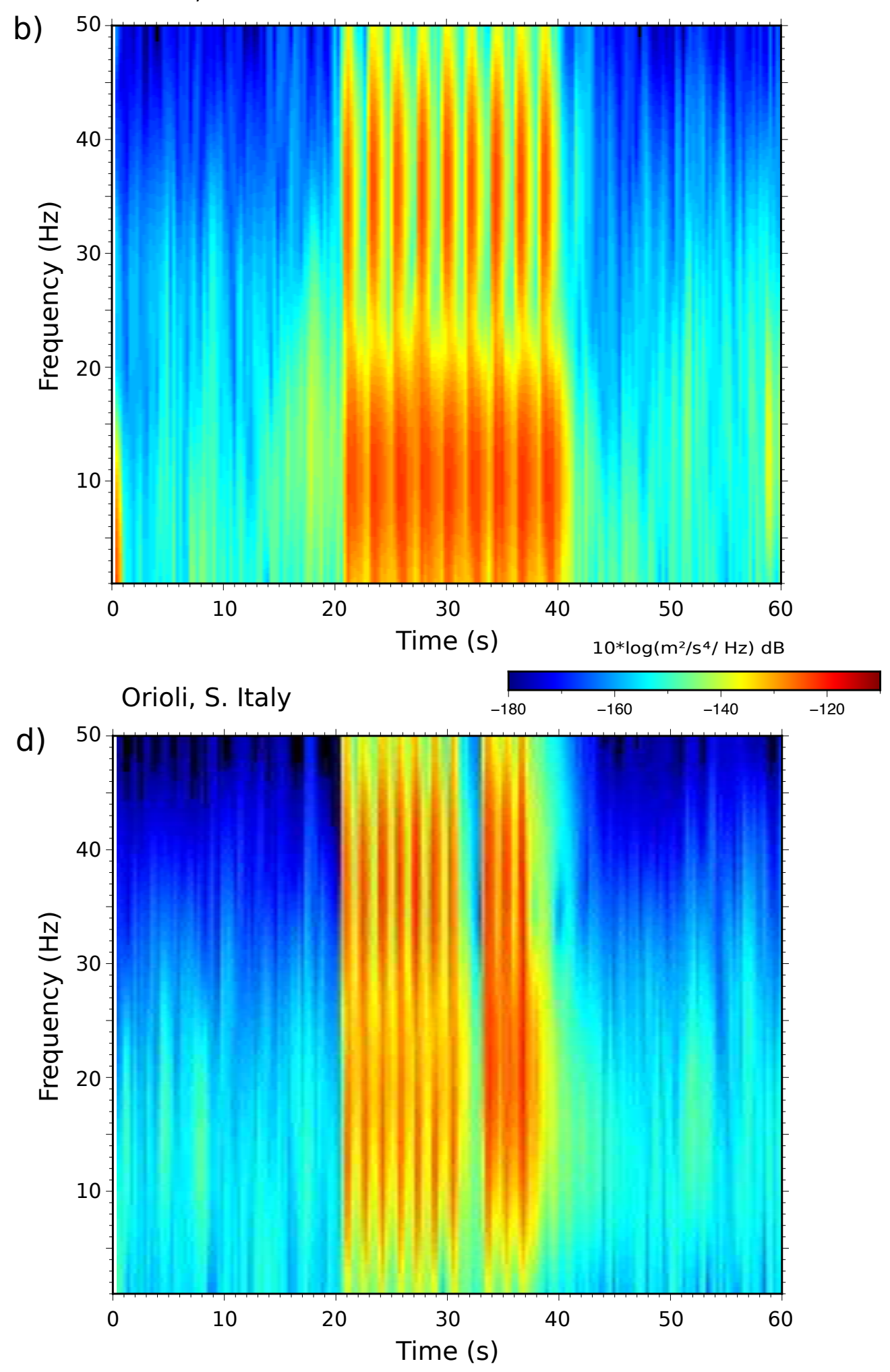
a)
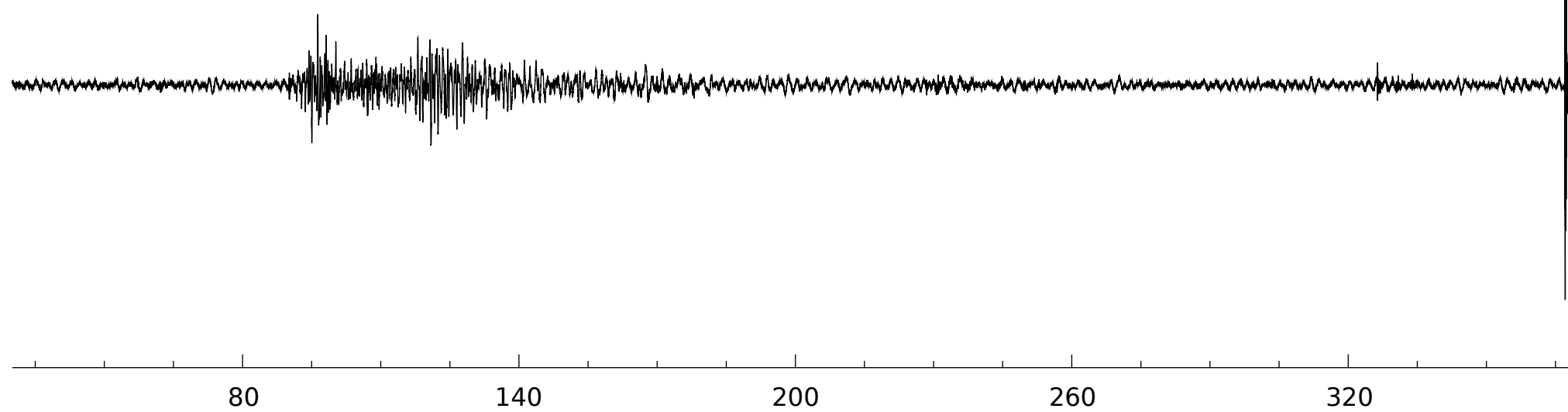

80

140

200

260

320

Time (s)

b)

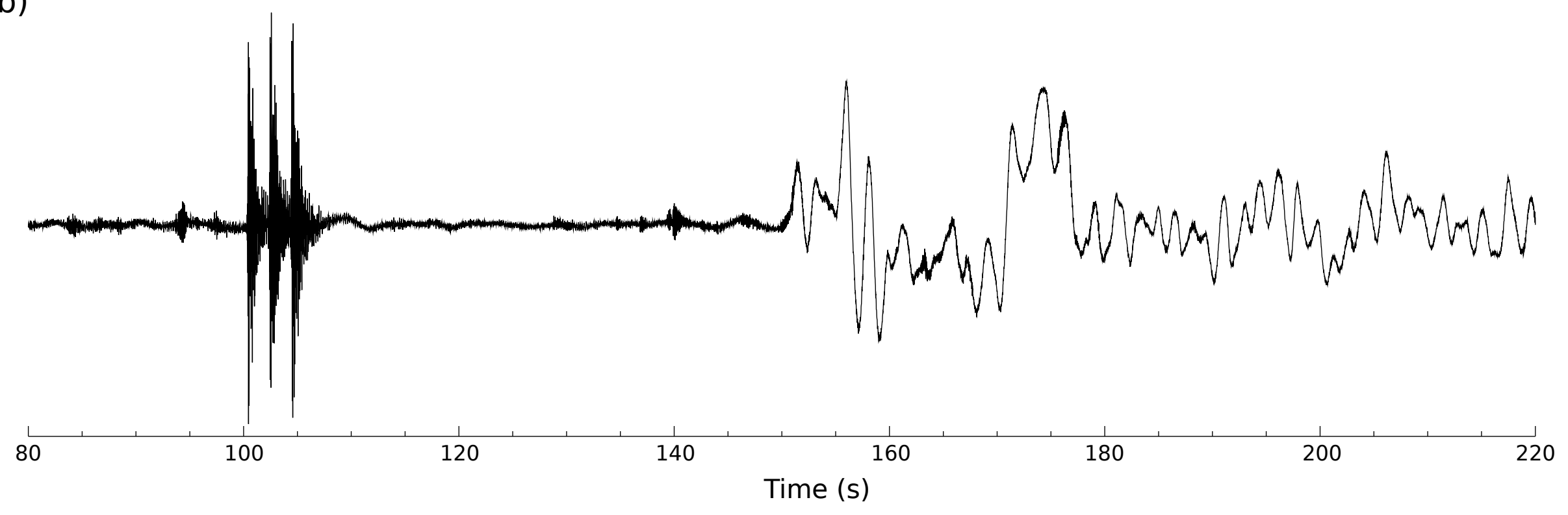




\begin{tabular}{|lllccccc|}
\hline Country & \multicolumn{1}{c}{ Location } & $\begin{array}{c}\text { Church } \\
\text { Name }\end{array}$ & $\begin{array}{c}\text { Station } \\
\text { code }\end{array}$ & $\begin{array}{c}\text { Network } \\
\text { code }\end{array}$ & $\begin{array}{c}\text { Station } \\
\text { Lat. }\end{array}$ & $\begin{array}{l}\text { Station } \\
\text { Long. }\end{array}$ & $\begin{array}{c}\text { Distance } \\
\text { to tower } \\
\text { bell (m) }\end{array}$ \\
\hline Greece & $\begin{array}{l}\text { Riolos } \\
\text { (W }\end{array}$ & $\begin{array}{l}\text { Agios } \\
\text { Ioannis }\end{array}$ & RLS & HL & 38.0559 & 21.4647 & 30 \\
France & $\begin{array}{l}\text { Peloponnessus) } \\
\text { Lunas } \\
\text { (Dordogne) }\end{array}$ & $\begin{array}{l}\text { Saint Jean } \\
\text { Baptiste }\end{array}$ & PY34B & X7 & 44.9175 & 0.4035 & 15 \\
Spain & $\begin{array}{l}\text { Sta. Maria } \\
\text { Montmagastrell } \\
\text { (Catalonia) } \\
\text { Oriolo } \\
\text { (Calabria) }\end{array}$ & Santa Maria & E120 & IB & 41.7203 & 1.1062 & 3 \\
Italy & San Giorgio & ORI & IV & 40.0510 & 16.4504 & 25 \\
\hline
\end{tabular}

